\title{
Digital Design of the Region's Logistics Infrastructure
}

\author{
Tasueva T.S. \\ Grozny State Oil Technical University \\ named after M.D. Millionshchikov, \\ Kh. Ibragimov Complex Institute of the RAS, \\ Grozny, Russia, \\ tamila7575@mail.ru
}

\author{
Borisova V.V. \\ Saint Petersburg State University of Economics, \\ Saint Petersburg, Russia, \\ verabrsv@yandex.ru
}

\begin{abstract}
The growth rates and balance of the region's economy largely depend on the level of development of the logistics infrastructure, which ensures synchronization of the actions of all participants in the supply system during transportation, procurement, cargo handling and storage of inventory items. In Russia, logistics as a sphere of infrastructural activity had been formed, was functioning and developing for a long time as providing, often transportation, forwarding and warehouse activitiy necessary for the physical distribution of inventory. The content of the concept of "logistics infrastructure" is interpreted in different ways in literary sources. The authors offer many interpretations of the concept of "logistics infrastructure", differing in content: from highly specialized definitions [1, 2, etc.] to expanded and over-generalized [4, 5, etc.]. The study [4] presents the interpretation of the term "logistics infrastructure" and indicates the position of the authors regarding the content of this term at the regional level of the economy, its integrating role "in relation to the social and economic subsystems of the territory". Meanwhile, modern digital transformations in the regional economy determine not only the creation of infrastructure conditions for the movement of goods, but also the end-to-end coordination of digital flows within the framework of regional reproduction processes. This phenomenon in the study of the characteristics of the logistics infrastructure testifies to the relentless scientific relevance of the problem. The logistics infrastructure is endowed with a multiplier effect achieved by optimizing flow processes in the product distribution system. The multiplication of economic flows is developing as a process showing that an increase in investment in logistics infrastructure ensures the growth of the gross regional product many times greater than the initial investment. In a difficult economic situation, the study of the latest trends in the optimization and digital transformation of the region's logistics infrastructure is of particular importance. In this context, the logistics infrastructure is a necessary prerequisite for the digital transformation of the region's economy. The development of a digital design for the region's logistics infrastructure is aimed at constructing an environment in which the interaction of participants in the supply chain is consistent with the development of end-to-end digital technologies.
\end{abstract}

Keywords—logistics, infrastructure, digital design, regional economy, end-to-end digital technologies, ecosystem

\section{INTRODUCTION}

Experts are sure that today the balancing of the logistics infrastructure and the capacities of the basic sectors of the economy is more important than ever for the region's economy. This is confirmed by the fact that the share of logistics costs is about $30 \%$ of the regional gross product. At the same time, in the total amount of logistics costs, transportation costs sometimes reach $80 \%$. In the structure of the region's logistics costs: average transportation costs are about $60 \%$; costs of warehouse logistics and inventory management - 25-30\%; expenses for the logistics administration of the distribution of supply systems $-10-15 \%$. Often, to optimize the structure and manage logistics flows, costs include losses associated with an insufficient level of quality in procurement, distribution, and administration of supply systems. This damage is assessed in terms of a reduction in market share, deterioration of performance indicators of the business sector of the regional economy, losses in the development of interregional trade, etc. It is obvious that the development of the region's economy directly depends on the efficiency of the logistics infrastructure. Experts studying the logistics infrastructure emphasize its integrating role in the economic life of the region. Among the principles for the development of logistics infrastructure are: "the feasibility of building infrastructure facilities and justifying the need for their placement in a certain area; availability of infrastructure facilities for businesses and consumers; consideration of the peculiarities of the socioeconomic potential of the region; innovative approach" [6].

Our analysis showed that the digital transformation of logistics activities in the economy of the country and most of its regions is implemented, as a rule, in the context of sectoral business models. The interaction of business entities with the logistics infrastructure is poorly implemented, and in most cases, logistics integration is spontaneous, stochastic in nature. 
Among the reasons for this state of affairs are: disproportions in the dynamics of supply and demand for logistics services; lack of integration of the logistics sector within a particular region; inconsistency of the logistics infrastructure with the needs of the territory; insufficient level of development of interregional trade; inconsistency in the standardization of logistics services (the difference in the applied accounting and contractual units).

To increase the level of integration of industry and regional logistics infrastructure, a new approach to information exchange and management of end-to-end digital technologies is required.

We have found that in a negative global economic situation caused by the coronavirus pandemic, the determining factors for the survival of business entities are time, flexibility, maneuverability of managerial decision-making and the use of predictive analytics in the formation of target priorities.

The variety of innovative projects for managing end-to-end digital technologies ${ }^{1}$ in new infrastructure systems is equal to the variety of schemes and methods of entrepreneurial activity. The main thing is that the implementation of an innovative project should give impetus to the socio-economic development of the region [7].

Among such innovative projects is the logistics support of the special economic zone created in 2019 on the territory of Grozny in the Chechen Republic. At this innovative site, it is planned to create fundamentally new objects of transport and logistics infrastructure that support the creation and operation of construction, production and social facilities. In the Chechen Republic, agreements are already being concluded with investors interested in joining this project. The projected volume of investments by 2028 will amount to about 14.2 billion rubles. It is assumed that stimulating the innovative activity of Russian and foreign investors will ensure the creation of at least 1,500 jobs in the republic.

Our analysis of the socio-economic situation in the Chechen Republic based on the identified patterns of development and systematization of stable patterns indicates the need to develop a digital design model for the region's logistics infrastructure. This will create conditions for the implementation of the project to create a special economic zone "Grozny" and will help improve the competitive position of the republic in Russian and international ratings reflecting its investment and tourist attractiveness.

To synchronize the actions of all elements of the logistics infrastructure, we recommend creating an open digital platform that levels out "regional and sectoral contradictions and at the same time contributes to increasing the competitiveness of business entities in the region.

The demand for integration lies in the essence of logistics itself and its subject-object area, which is expressed in the management, monitoring and control of logistics flows; coordination of all processes of commodity circulation,

${ }^{1}$ List of end-to-end digital technologies: big data; new production technologies; industrial internet; Artificial Intelligence; wireless technology; robotics and sensorics components; quantum technologies; distributed ledger systems; technologies of virtual and augmented reality. starting from the purchase of material resources and ending with delivery to the end consumer [8].

Specific forms of integration are determined by the technical, technological and organizational-economic conjugation of the main links of the supply system and state and legal regulations. The most common forms of integration are: technological, functional, horizontal, vertical, combined, organizational. Thus, technological integration allows for optimal delivery and use of advanced types of packaging, cargo design systems, unification and standardization of logistics operations. Functional integration brings together the efforts of various parts of the logistics system in the management of material and other related flows.

For example, in the Chechen Republic, in order to achieve a holistic organizational integration of transportation, storage and sale of agricultural products, innovative wholesale distribution centers have been created. Their task is to help launch leading integrated digital platforms. Within the framework of such platforms, communication interaction is possible on improving basic technologies and creating fundamentally new products [9].

Development priorities should be complemented by guidelines for creating an intelligent logistics infrastructure operating on the principles of information superiority and network-centric operations. With the exhaustion of the traditional physical possibilities for rationalizing product distribution schemes, the use of an open digital platform will allow achieving the strategic goals of forming a balanced product distribution system through network-centric management methods, using a digital twin of the supply system and ensuring the intellectualization of logistics activities.

It is obvious that it is impossible to solve this problem without modern information and communication technologies. The supply system requires the development of logistics services up to the level of 5PL providers - virtual logistics operators that provide a full range of services for transportation, warehousing, inventory management, and supply chain administration.

An open digital platform is able to ensure the interaction of logistics intermediaries with scientific centers, local regulators and customs services based on end-to-end management of goods flows.

\section{Problem Statement}

The logistics infrastructure of the region is a complex socio-economic system that includes a set of link elements (business entities) that implement transport, storage, procurement, forwarding and other services, united by the economic flow and having many economic ties characterized by complexity, duration, structure, stability and consistency. Now this system is undergoing significant transformations due to the digitalization of the economic landscape of the territory.

The digital design of the organizational-spatial socioeconomic system of the region unites various industries and spheres of activity at all stages of the regional reproduction process. The elements of this hierarchically complex system are logistic intermediaries: sectoral transport enterprises (road transport enterprises, operators of rolling stock of railway transport, operators of pipeline transport, etc.), industries, 
trade, agriculture, construction, transport and logistics divisions in vertically integrated companies and transport and logistics clusters.

The digital design of the region's logistics infrastructure forms a graphic-analytical model of the expediency of flow processes, including the elimination of duplicate, counter flows. Logistics centers play an important role in the rationalization of product distribution schemes. The digital transformation of the activities of logistics centers is reflected in the automation of warehousing (robotization), the processing of inventory items, optimization of commodity circulation schemes, monitoring of transportation, etc. However, the automation and informatization of logistics centers are not always accompanied by the introduction of new digital business models.

The sequence of digital transformation of the region's logistics infrastructure can be described as follows: development and commercialization of digital design of the logistics sector of the economy; management of the system of relationships with consumers of logistics services, management of the range and quality of logistics services based on flexible, adaptive methods; the formation of customer-driven logistics systems; fulfillment of incoming orders for logistics services based on end-to-end traceability and sensing; predictive analytics of glitches and failures in work, recycling and claims activities $[10,11]$.

\section{RESEARCH QUESTIONS}

Formation of a single information space using cloud technologies and artificial intelligence begins to play a key role in shaping the digital design of the region's logistics infrastructure. At the same time, the internal processes of the logistic information space not only functionally complement each other, but also fit into changes in the external environment on the principles of: global access to resources without intermediaries by providing resources for rent; using the volunteer model and network-centric management methods" [12]. According to the experts, the international information technology market in 2020 is estimated at 5.2 trillion US dollars [13].

In the information base related to logistics are concentrated: invoices; purchase and sales module; procurement management; sales management; storage; accounting of costs and overheads; inventory; reservation of goods; management of discounts and markups; consignment; analysis of turnover; marketing logistics; forecasting the volume of purchases and sales, etc. Therefore, modern objects of the logistics infrastructure are a composition of the organizational structure of management with functionally oriented artificial intelligence technologies and the penetration of the standard of wireless high-speed data transmission into the logistics processes of mobile communication for mobile and other terminals working with $4 \mathrm{G}-5 \mathrm{G}$ data.

A new role in the digital transformation of logistics infrastructure is played by "real physical things (industrial internet), which operate within the framework of hard-coded models using artificial intelligence and machinery. Such intelligent things are adapted to perform complex logistic functions and exhibit a fairly natural interaction with the logistic environment. "Smart" things can be equipped with sensors, accelerators, keyboards, fiber optics, heating elements, solar panels, music players and other devices.

The expansion of the use of intelligent devices in logistics practice (unmanned aerial vehicles, autonomous vehicles, etc.) contributes to the transition from the use of autonomous intelligent things to their joint use. Opportunities in this direction are expanded by the technical world of virtual and augmented reality $[14,15,16]$. In logistics, the development of artificial intelligence is necessary to create truly useful and "smart" robots.

The creation of an open digital platform that synchronizes the actions of the logistics infrastructure eliminates contradictions in the joint use of transport and warehouse space. In the context of a pandemic and quarantine, logistics operators began to successfully implement remote electronic processing of documents for the transportation of goods without personal contact. For example, INTERTRAN technology integrates participants of the supply chain in the implementation of railroad transportation. Delivery services during the period of quarantine and isolation not only receive more revenue, but also increase (expand) their customer base through discounts and other ways of attracting new customers.

Digital technologies allow participants of the supply chain to adapt to new demand and new realities. A system of contactless delivery of goods is being introduced. Couriers are provided with masks and other protective equipment; cash payment is gradually being phased out. Developers of new software products and services have expanded their scope of activity. For example, the Yandex.Eda (Yandex.Food) service is now presented in 32 new cities. The drug delivery service "Samokat" ("Scooter") and others work together with a network of pharmacies. Online sellers are expanding their range of services. For example, the website "SBERegi sebya doma" (Stay safe at home) advertises new Sberbank services available to customers in isolation.

Consumer trends indicate an increased interest in online commerce. If earlier experts predicted that the volume of online sales will exceed traditional trade by 2036, in reality this moment may come much earlier. Online purchases were tested by those customers who have never made them before; most likely, they will retain their loyalty to digital purchases in the post-crisis period.

Trading robotization is gaining momentum. During the pandemic, it is safer to use robots for packing and delivery of orders is safer than working with people. Robots are able to work faster and longer, complete more tasks and thus optimize costs. The current volume of the global industrial robotics market is about $\$ 20$ billion.

Experts believe that in the post-crisis situation, investments in the robotization of logistics processes will continue. Services are already becoming the basic infrastructure for organizing work and carrying out vital communications. The work of company employees in distance mode has given an additional impetus to the development of cloud technologies, which make it possible to quickly 
implement new management solutions and act promptly in conditions of uncertainty. The volume of the Russian market of cloud services by 2023, according to analysts, will approach one billion dollars.

\section{Purpose of the Study Research Methods}

The study is aimed at ensuring the economic and organizational unity of commodity circulation in the regional economy by developing a methodology for digital design of the environment for the functioning of the logistics infrastructure. The digital design of the region's logistics infrastructure is differentiated based on the general goal, subject and object composition, data availability and platform purpose.

We have identified the features of the functioning of digital platforms in relation to the object of study. The main ones are: network interaction of users; retention of participants due to the virality ${ }^{2}$ of digital platforms; algorithmized toolkit for partner interaction; network-centric approach to building the system; application of end-to-end digital technologies for data processing; rationalization of transactions and accompanying costs; scaling innovation; substantiation of the general development goal [17].

In the process of digital design of the region's logistics infrastructure, information exchange takes place both inside and outside the digital platform. Communication with other digital platforms is associated with the implementation of the ecosystem approach [18, 19, 20].

The digital platform of logistics infrastructure brings together market participants; the purpose of its functioning is the prompt development and provision of solutions to participants for the use of end-to-end digital technologies, services, software products; providing access to ecosystem data sources [21].

The complexity of analyzing the digital transformation of the regional logistics infrastructure lies in substantiating the general (target) function of the designed system and ensuring data integrity by integrating data processing tools, information exchange triggers, data processing buses, etc.

To ensure the completeness of the analysis, it is necessary to characterize the platform solutions of the system: resource management; relationship management; document management system; business intelligence; services and software products; project work management; business process management, etc.

Digital platforms are data aggregators ${ }^{3}$ that create an environment that provides users with valuable information and competitive advantage by systematizing the process of interacting with partners.

Shared digital platforms facilitate interactions between users; contribute to the emergence of network effects in which the value of the platforms increases with the increase in the number of their participants.

${ }^{2}$ Virality - the ability of an idea (innovation) to quickly spread in the digital space, moving from one user to another; this stimulates the growth of platforms from the outside, and the network effect keeps users within the platform.

${ }^{3}$ Data aggregation is the collection and systematization of data from different sources, providing them in an ergonomic way.

\section{FINDINGS}

The digital design of the region's logistics infrastructure is characterized by an expansion of the range of innovations: cloud technologies and artificial intelligence, methods for researching neural networks and processing natural languages. Some technologies have already gone beyond traditional algorithms and are capable of creating systems that can understand, learn, predict, adapt to a changing environment, and are potentially ready to function autonomously. The evolution of the logistics infrastructure, especially its digital transformation, testifies to its strategic role in strengthening the competitive positions of not only business structures, but also regional, interregional and intersectoral cooperatives. Conceptually, a problem was identified related to the cybersecurity of the critical logistics infrastructure of the region and the justification of the security of its digital framework.

\section{CONCLUSION}

Logistic infrastructure as an object of study of the general theory of logistics is considered from the point of view of the composition of its elements, the complexity of their interaction and the differentiation of functions; the presence of organized management and stochasticity of environmental factors affecting it. Describing the logistics infrastructure of the region as a complex socio-economic system that implements the principles of managing material, information, financial and service flows, we note that actually functioning infrastructure facilities are organizationally completed economic structures that unite the transport sector, wholesale and retail trade, warehousing, means of communication and communication.

The most productive approach to dividing the logistics infrastructure into two large groups is tiered: macro and micro level.

So, at the micro level, the logistics infrastructure includes transport companies; logistics operators performing intermediary services of various levels of complexity; wholesale and retail trade enterprises, etc.

\section{Acknowledgment}

The study was carried out with the financial support of the Russian Foundation for Basic Research within the framework of scientific project no.20-010-00141\20.

\section{References}

[1] D. Bowersox and D. Kloss, "Logistics: an integrated supply chain", Moscow: ZAO Olymp-Business, 2008 .

[2] V.I. Sergeev, A.N. Sterligova, V.V. Dybskaya and E.I. Zaitsev, "Corporate logistics: 300 answers to professional questions", M.: INFRA-M, 2018. (In Russ.).

[3] A.V. Dmitriev, "Development of framework safety standards based on the SAFETIR system in real time and the concept of an authorized supply chain", Technical and technological problems of service, 2019, vol. 4(50), pp. 77-82. (In Russ.)

[4] P.G. Shvalov and V.F. Lukinykh, "To the question of identification of logistic infrastructure at the regional level”, Bulletin of KrasGAU, 2012, vol. 5, pp. 9-13. (In Russ.).

[5] "Logistics and supply chain management", in V.V. Shcherbakov (Ed.) Moscow: Yurayt, 2019. (In Russ.).

[6] L.Yu. Berezhnaya, "To the question of the formation of a regional logistics infrastructure", Actual problems of economic sciences, 2016 vol. 51, pp. 98-102. (In Russ.) 
[7] V. Borisova, T. Tasueva and B. Rakhimova, "State Support for Digital Logistics" in Proceedings of the 21st Century from the Positions of Modern Science: Intellectual, Digital and Innovative Aspects Conference paper First Online, 2019, pp. 631-638. (In Russ.).

[8] V.V. Borisova and K.G. Gordei, "Digital technologies warehouse logistics", Science of the XXI century: problems and prospects of researches, 2017, vol. 2, pp. 3-7. (In Russ.).

[9] V.V. Borisova, D.K-S. Bataev and T.S. Tasueva, "Logistic Agroindustrial Cluster As A Strategic Tool For Regional Development", in Proceedings of the CIEDR 2018 International Scientific and Practical Conference "Contemporary Issues of Economic Development of Russia: Challenges and Opportunities", pp. 492-499. (In Russ.). DOI: https://dx.doi.org/10.15405/epsbs.2019.04.53

[10] A.V. Dmitriev, "Management of transport and logistics systems in the context of digitalization", Bulletin of the St. Petersburg State University of Economics, 2020,.vol.12,. pp 79-86. (In Russ.).

[11] A.V. Dmitriev and I.A. Plastunyak, "Integrated digital platforms for development of transport and logistics services", in Proceedings of the International Conference on Digital Technologies in Logistics and Infrastructure (ICDTLI 2019). Atlantis Highlights in Computer Sciences, 2019, vol. 1, pp. 136-141. (In Russ.). DOI: https://doi.org/10.2991/icdtli-19.2019.27

[12] N.M. Abdikeev, V.A. Ivanyuk, F.F. Pashchenko and N.V. Grineva, "Network-centric management methods", Management sciences, 2017, vol. 1, pp. 26-34. (In Russ.).

[13] E.G. Popkova, I.V. Lysak, I.N. Titarenko, V. Golikov and I.A. Mordvintsev, "Philosophy of Overcoming "Institutional Traps" and "Black Holes" Within the Global Crisis Management [E-source]", Overcoming Uncertainty of Institutional Environment as a Tool of Global Crisis Management in E.G. Popkova (Ed.), [Springer International Publishing AG], 2017, pp. 321-325. (Ser. ContributionstoEconomics). (In Russ.). Retrieved from http://archilab.online/images/419642_1_En_Online.pdf
[14] N.S. Pechenko, V.V. Borisova and A.V. Molonova "Digital transformation of Eurasian Economic Union's (EAEU) logistics system", in Proceedings of the International Conference on Digital Transformation in Logistics and Infrastructure (ICDTLI 2019). Atlantis Highlights in Computer Sciences, 2019, vol. 1. pp. 20-24. (In Russ.).

[15] V. Plotnikov, G.V. Fedotova, E.G. Popkova and A.A. Kastyurina, "Harmonization of Strategic Planning Indicators of Territories" Socioeconomic Growth", Regional and Sectoral Economic Studies, 2015, vol. 15(2), pp. 105-114. (In Russ.). Retrieved from http://www.usc.es/ economet/reviews/eers1527.pdf

[16] J. Parker, M. van Alstin and S. Chaudary, "Platform revolution. How Network Markets Are Changing the Economy - And How To Make Them Work For You", Moscow: Mann, Ivanov, Ferber, 2017.

[17] H. Ghasemkhani, D. Soule and G.F. Westerman, "Competitive advantage in a digital world: Toward an informationbased view of the firm". MIT Initiative on the Digital Economy, Working Paper, 2015 , vol. 5, pp. 1-25. DOI: http://dx.doi. org/10.2139/ssrn.2698775

[18] A. Hein, M. Schreieck, T. Riasanow, D.S. Setzke, M. Wiesche, M, Böhm and H. Krcmar, "Digital platform ecosystems", Electron Markets, 2020, vol. 30, pp. 87-98. DOI: https://doi.org/10.1007/s12525-01900377-4

[19] R. Kapoor, "Ecosystems: Broadening the locus of value creation", Journal of Organization Design, 2018, vol. 7(1), pp. 2-16. DOI: https://doi.org/10.1186/s41469-018-0035-4

[20] R. Kapoor and S. Agarwal, "Sustaining superior performance in business ecosystems: Evidence from application software developers in the Ios and android smartphone ecosystems". Organization Science, 2017, vol. 28(3), pp. 531-551.

[21] Y. Jiang, Y.-C. Ho, X. Yan and Y. Tan, "Investor platform choice Herding, platform attributes, and regulations", Journal of Management Information Systems, 2018, vol. 35(1), pp. 86-116.

[22] M. Young, “The Technical Writer's Handbook”, Mill Valley, CA: University Science, 1989. 